\title{
Síntese, caracterização e propriedade fotoluminescente de tungstato de bário puro e dopado com hólmio
}

\section{(Synthesis, characterization and photoluminescent property of barium tungstate and holmium-doped barium tungstate)}

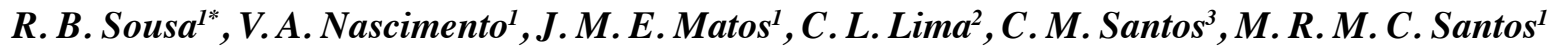 \\ ${ }^{1}$ Laboratório Interdisciplinar de Materiais Avançados - LIMAV, ${ }^{2}$ Departamento de Física \\ Centro de Ciências da Natureza - CCN, Universidade Federal do Piauí - UFPI, Teresina, PI 64049-550 \\ ${ }^{3}$ Departamento de Física, Universidade Federal do Ceará, Campus do Pici, Fortaleza, CE 60440-970 \\ *ricardo@ufpi.edu.br,val.albuquerque@hotmail.com,jmematos@ufpi.edu.br,cleanioll@yahoo.com.br, \\ cmorillasantos@yahoo.com.br,mrita@ufpi.edu.br
}

\begin{abstract}
Resumo
O tungstato de bário $\left(\mathrm{BaWO}_{4}\right)$ é um importante material cerâmico da família das scheelitas que apresenta aplicações em dispositivos fotoluminescentes como cintiladores, diodos emissores de luz, lasers do estado sólido, entre outros, destacando-se como matriz hospedeira para íons lantanídeos, por apresentar estabilidades química e mecânica. Este trabalho teve como intuito sintetizar, caracterizar estruturalmente e avaliar a propriedade fotoluminescente de pós de tungstato de bário puro e dopado com íons hólmio $\left(\mathrm{Ho}^{3+}\right)$. Os pós de $\mathrm{Ba}_{1-\mathrm{x}} \mathrm{Ho}_{2 \times / 3} \mathrm{WO}_{4}(\mathrm{x}=0,0,01$, e 0,02$)$ foram obtidos por coprecipitação e caracterizados por difração de raios X, espectroscopias Raman, na região do Infravermelho e de absorção na região do ultravioleta-visível, microscopia eletrônica de varredura e espectroscopia de fotoluminescência. As análises de difração de raios X e espectroscopia Raman revelaram ordenamento cristalino. A morfologia foi caracterizada pela presença de grãos octaédricos com distribuição heterogênea do tamanho dos grãos. Uma banda centrada em $475 \mathrm{~nm}$ foi identificada no espectro de fotoluminescência para a amostra de $\mathrm{BaWO}_{4}$ sob excitação de 350,7 $\mathrm{nm}$. Com a dopagem deste óxido, houve redução significativa do valor do gap ótico e transições características de emissão dos íons $\mathrm{Ho}^{3+}$ (transições f-f) foram identificadas.
\end{abstract}

Palavras-chave: tungstato de bário, fotoluminescência, hólmio.

Abstract

Barium tungstate $\left(\mathrm{BaWO}_{4}\right)$ is an importantceramic material belonging to the familyof scheelites, which is applied as photoluminescent material, as scintillator, light-emitting diodes (LEDs), solid-state lasers, among other, being a host matrix for lanthanide ions, due to its chemical and mechanical stability. This research aims to synthetize, characterize structurally and evaluate photoluminescent properties of barium tungstate powders and $\mathrm{Ho}^{3+}$-doped barium tungstate. Powders of $\mathrm{Ba}_{1-x} \mathrm{Ho}_{2 x / 3} \mathrm{WO}_{4}(x=0,0.01$ and 0.02$)$ were obtained by coprecipitation and characterized by X-ray diffraction (XRD), Raman spectroscopy, Fourier-Transformed Infrared spectroscopy (FTIR), UV-Vis spectroscopy, scanning electron microscopy (SEM) and photoluminescent spectroscopy. XRD and Raman spectroscopy analyses revealed crystalline ordering for these materials. Their morphology was characterized by the presence of octahedral grains with heterogeneous distribution of grain size. A broad band centered at $475 \mathrm{~nm}$ was identified for $\mathrm{BaWO}_{4}$ at 350,7 nm excitation in emission spectrum. The addiction of holmium ions into the BaWO matrix promoted a significant reduction of the optical gap and characteristic transitions ( $f$-f transitions) of ions $\mathrm{Ho}^{3+}$ were identified.

Keywords: barium tungstate, photoluminescence, holmium.

\section{INTRODUÇÃO}

A síntese de cerâmicas avançadas com tamanho e geometria controlados dos grãos tem adquirido grande importância nas últimas décadas devido às suas potenciais aplicações em diferentes campos da ciência e tecnologia, tais como catálise, eletrônica, medicina, cerâmica, pigmentos e cosméticos [1,2].

Tungstatos e molibdatos de cátions divalentes são importantes cerâmicas que se cristalizam sob uma estrutura scheelita ou sob uma estrutura wolframita, dependendo do tamanho do raio iônico do modificador de rede. Os compos- tos com estrutura tetragonal scheelita apresentam raio catiônico maior que $0,99 \AA$, tais como para os íons $\mathrm{Ca}^{2+}, \mathrm{Sr}^{2+}$, $\mathrm{Ba}^{2+} \mathrm{e} \mathrm{Pb}^{2+}$. Nessa configuração, os átomos de tungstênio ou molibdênio adotam uma coordenação tetraédrica. Por outro lado, quando o raio cationnico for menor que $0,77 \AA$, tais como $\mathrm{Fe}^{2+}, \mathrm{Mn}^{2+}, \mathrm{Co}^{2+}, \mathrm{Ni}^{2+}, \mathrm{Mg}^{2+} \mathrm{e} \mathrm{Zn}^{2+}$, os átomos de tungstênio ou molibdênio adotam uma coordenação octaédrica, formando uma estrutura monoclínica wolframita [3]. Particularmente, os tungstatos com estrutura tetragonal scheelita são materiais reconhecidos por suas excelentes propriedades ópticas e estruturais e por suas potenciais aplicações em dispositivos luminescentes, imagens médicas de raios $\mathrm{X}$ e 
displays [4-6]. Entre suas propriedades ópticas, destaca-se a emissão fotoluminescente. Esta consiste em uma forma de emissão luminescente produzida quando um material excitado emite radiação eletromagnética na forma de fótons. A onda eletromagnética irradiada, via de regra, apresenta comprimento de onda maior do que a radiação que causou a excitação [7].

$\mathrm{O}$ tungstato de bário $\left(\mathrm{BaWO}_{4}\right)$ é um material cerâmico semicondutor que apresenta cristalização tetragonal do tipo scheelita a baixas pressões, com grupo espacial I $4_{I} / a$ e grupo pontual $\mathrm{C}_{4 \mathrm{~h}}{ }^{6}$. Nessa estrutura, ilustrada na Fig. 1, cada átomo de tungstênio, denominado formador de rede, encontrase ligado a quatro átomos de oxigênio formando clusters $\left[\mathrm{WO}_{4}\right]$, enquanto os átomos de bário $\left(\mathrm{Ba}^{2+}\right)$, modificadores de rede, encontram-se coordenados a oito átomos de oxigênio, formando clusters $\left[\mathrm{BaO}_{8}\right]$ [8-11].

Nas últimas décadas, este material tem atraído a atenção de pesquisadores, por suas propriedades permitirem aplicações variadas tais como cintiladores para aplicações médicas [2, 4, 9, 12], lasers de estado sólido [1, 13, 14], fotocatalisadores [2], fibras óticas [1, 3], detectores de radiação $[12,15]$ entre outras aplicações eletro-ópticas. O tungstato de bário é uma scheelita bastante promissora para aplicações em lasers de estado sólido empregados em espectroscopia Raman, uma vez que emite radiação em regiões espectrais específicas com pulsos de pico a nanossegundos $[1,2,12,13,16-20]$. Este material exibe luminescência azul à temperatura ambiente com uma banda larga entre 400 e $450 \mathrm{~nm}$ nos espectros de emissão luminescente, que corresponde à transferência de cargas do oxigênio para o metal $\left(\mathrm{O}^{2-} \rightarrow \mathrm{W}^{6+}\right)$, correspondendo no espectro de excitação a uma banda na região entre 220 a 275 nm [21]. Além disso, apresenta luminescência verde

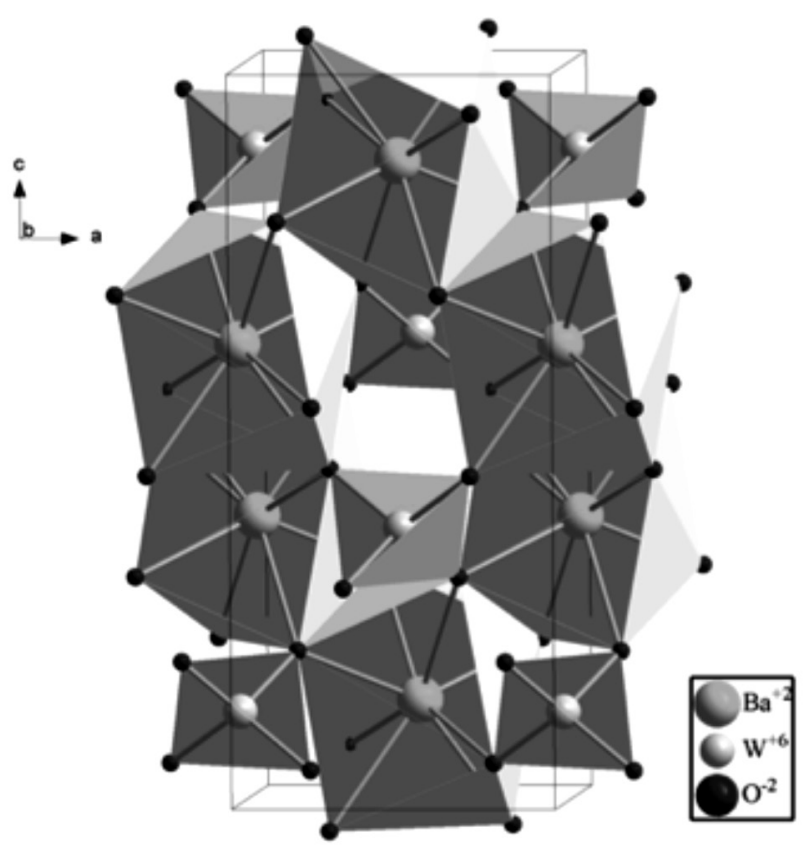

Figura 1: Estrutura tetragonal do tipo scheelita de $\mathrm{BaWO}_{4}$. [Figure 1: Tetragonal structure scheelite-type of $\mathrm{BaWO}_{4} .{ }^{4}$.] com máximo de emissão em $543 \mathrm{~nm}$ nos espectros de emissão fotoluminescente, que são atribuídas às distorções intrínsecas dos clusters $\left[\mathrm{WO}_{4}\right]$ [22]. O comprimento de onda e a intensidade da luminescência destes materiais estão associados ao método de preparação [8]. $\mathrm{O} \mathrm{BaWO}_{4}$ é um material altamente luminescente, que apresenta luminescências azul e verde, tendo adquirido recentemente grande importância para a indústria óptico-eletrônica [23]. Possui potencialidade para aplicação em lasers de estado sólido com emissão em uma região espectral específica de grande importância por causa de suas interessantes propriedades de espalhamento Raman estimulado [13]. A origem de sua luminescência tem sido atribuída entre outros fatores à presença de defeitos pontuais ocasionados pela presença de átomos de oxigênio intersticiais nos clusters $\left[\mathrm{WO}_{4}\right]$. O comprimento de onda e a intensidade da luminescência exibida por estes materiais estão explicitamente ligados ao método de preparação empregado [24]. A ocorrência de vacâncias, assim como a inserção de impurezas na forma de dopantes na estrutura dos compostos cristalinos, podem potencializar e ampliar a propriedade fotoluminescente, criando novos estados eletrônicos que podem facilitar as transições eletrônicas na estrutura dos materiais [7].

Materiais luminescentes dopados com lantanídeos são de grande interesse para a indústria óptico-eletrônica devido a suas excelentes capacidades de emissão de cores puras. Esses materiais têm sido aplicados em dispositivos para comunicação óptica, displays, lasers, marcadores biológicos fluorescentes [25], em processos de conversão espectral, como up-conversão e down-conversão, para aplicações fotovoltaicas [26], diodos emissores de luz [16, 27, 28], lâmpadas fluorescentes, tubos de raios catódicos [29], cintiladores [30], fotocatalisadores, como por exemplo $\mathrm{NaLa}\left(\mathrm{MoO}_{4}\right)_{2}: \mathrm{Eu}^{3+}$, $\mathrm{Tb}^{3+}$ [31]. Os elementos da série dos lantanídeos, conhecidos também como terras raras, têm-se destacado por suas propriedades espectroscópicas às quais tem oferecido ilimitadas possibilidades na concepção de novos materiais luminescentes. A maioria das propriedades destes elementos e de seus íons correspondentes provém de suas configurações eletrônicas caracterizadas por orbitais $4 f$ parcialmente preenchidos. Embora também sejam empregados na forma de óxidos e outros compostos com proporções estequiométricas definidas, têm-se tornado atraente a possibilidade de utilizá-los como dopantes em matrizes como as scheelitas [32]. Entre as scheelitas, o $\mathrm{BaWO}_{4}$ é considerado uma boa matriz hospedeira de íons lantanídeos por apresentar estabilidade química e térmica [21]. São reportados na literatura alguns trabalhos que descrevem a síntese e a investigação das características estruturais e da propriedade de fotoluminescência do tungstato de bário dopado com íons lantanídeos tais como disprósio $\left(\mathrm{Dy}^{3+}\right)$ [21], európio $\left(\mathrm{Eu}^{3+}\right)$ $[4,32]$ e praseodímio $\left(\mathrm{Pr}^{3+}\right)$ [8]. Entretanto, ainda não foi reportada a síntese, a caracterização e o estudo da propriedade de fotoluminescência de matrizes de tungstatos de bário dopadas com íons hólmio $\left(\mathrm{Ho}^{3+}\right)$. O hólmio, elemento de número atômico 67 , e cujo principal isótopo ${ }^{165} \mathrm{Ho}$, apre- 
senta propriedades magnéticas e térmicas incomuns, que o tornam altamente paramagnético acima de $133 \mathrm{~K}$, possuindo um momento magnético por átomo de 10,6 $\mu_{\mathrm{B}}$. Este efeito é mais pronunciado a baixas temperaturas e menos pronunciado a altas temperaturas e possibilita a obtenção de imagens por ressonância magnética. $\mathrm{O}$ hólmio tem potencial aplicação em tratamentos radioterápicos e tem sido utilizado com sucesso em lasers para o tratamento de doenças urológicas [33, 34].

Neste sentido, é reportado neste trabalho a síntese, a caracterização estrutural e a investigação da propriedade de fotoluminescência de tungstato de bário puro e dopado com íons hólmio, obtidos pelo método de coprecipitação à temperatura ambiente, visando o estudo da influência destes íons sobre a estrutura e fotoluminescência do $\mathrm{BaWO}_{4}$.

\section{EXPERIMENTAL}

\section{Procedimento de síntese}

Todos os reagentes utilizados na síntese de pós de tungstato de bário puro e dopados com lantanídeos foram de grau analítico. Para obtenção dos pós de $\mathrm{BaWO}_{4}$ puro, foram preparadas soluções individuais em quantidades equimolares de $\mathrm{BaCl}_{2} \cdot 2 \mathrm{H}_{2} \mathrm{O}$ ( $\mathrm{PR}$ Químicos) e $\mathrm{Na}_{2} \mathrm{WO}_{4} \cdot 2 \mathrm{H}_{2} \mathrm{O}$ (Vetec). Cada sistema foi mantido de 5 a $10 \mathrm{~min}$ sob agitação independentemente. Transcorrido este tempo, suficiente para homogeneização das soluções, a solução de $\mathrm{Na}_{2} \mathrm{WO}_{4} \cdot 2 \mathrm{H}_{2} \mathrm{O}$ foi aos poucos adicionada à solução $\mathrm{BaCl}_{2} \cdot 2 \mathrm{H}_{2} \mathrm{O}$, resultando em $100 \mathrm{~mL}$ da mistura e ocorrendo a formação instantânea de um precipitado branco (conforme Fig. 2).

Para obtenção dos pós de $\mathrm{Ba}_{1-\mathrm{x}} \mathrm{Ho}_{2 \mathrm{x} / 3} \mathrm{WO}_{4}, \mathrm{x}=0,01 \mathrm{ou}$ 0,02 , foram preparadas soluções equimolares de $\mathrm{BaCl}_{2} \cdot 2 \mathrm{H}_{2} \mathrm{O}$ e $\mathrm{Na}_{2} \mathrm{WO}_{4} \cdot 2 \mathrm{H}_{2} \mathrm{O}$ e uma terceira solução de $\mathrm{Ho}_{2} \mathrm{O}_{3}$, o qual foi pesado estequiometricamente para dopagens a 1 e $2 \%$ $\mathrm{mol} / \mathrm{mol}$. A dissolução do $\mathrm{Ho}_{2} \mathrm{O}_{3}$ foi realizada adicionando-

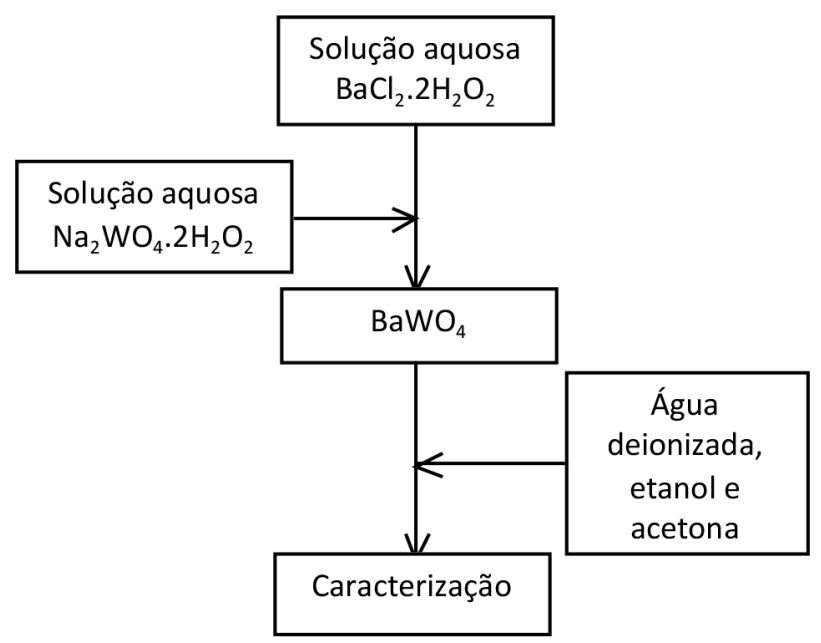

Figura 2: Etapas da síntese de $\mathrm{BaWO}_{4}$ pelo método de coprecipitação à temperatura ambiente.

[Figure 2: Steps of $\mathrm{BaWO}_{4}$ synthesis by the coprecipitation method at room temperature.] se algumas gotas de $\mathrm{HCl}$ e aquecimento brando. A seguir esta solução foi adicionada à solução de $\mathrm{BaCl}_{2} \cdot 2 \mathrm{H}_{2} \mathrm{O}$. E, finalmente, foi adicionada a esta a solução de $\mathrm{Na}_{2} \mathrm{WO}_{4} \cdot 2 \mathrm{H}_{2} \mathrm{O}$, formando instantaneamente precipitados brancos (Fig. 3). Todos os precipitados foram então continuamente lavados com água deionizada, etanol e acetona e secos à temperatura ambiente por um período de 24 a $72 \mathrm{~h}$. Os pós foram submetidos à caracterização.

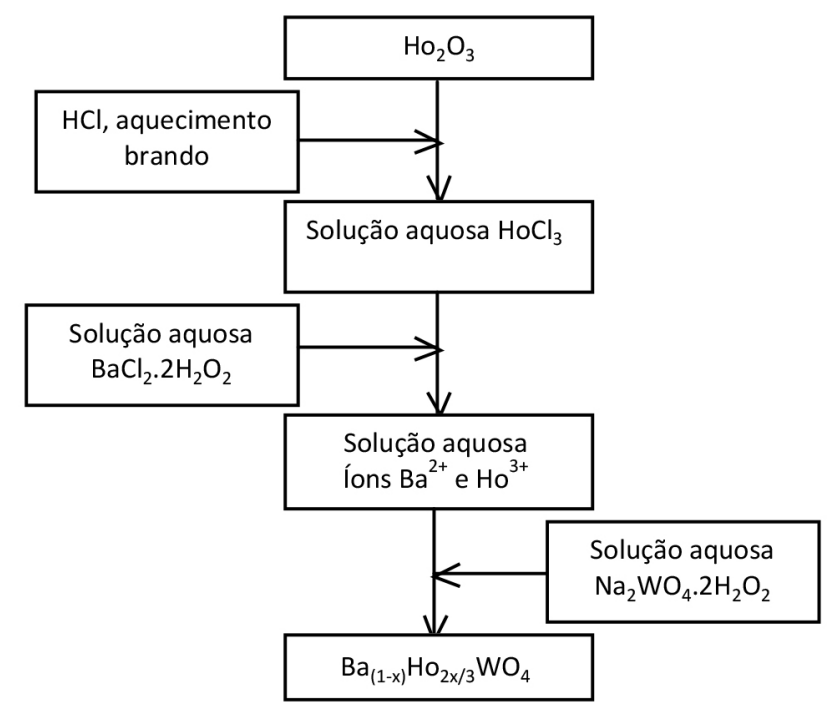

Figura 3: Etapas da síntese de $\mathrm{Ba}_{1-x} \mathrm{Ho}_{2 \times / 3} \mathrm{WO}_{4}$ pelo método de coprecipitação à temperatura ambiente.

[Figure 3: Steps in $\mathrm{Ba}_{1-x} \mathrm{Ho}_{2 \times / 3} \mathrm{WO}_{4}$ synthesis by the coprecipitation method at room temperature].

\section{Caracterização dos materiais}

Os pós cerâmicos preparados foram submetidos à caracterização por meio das técnicas de difração de raios X, espectroscopia Raman, espectroscopia no infravermelho com transformada de Fourier, microscopia eletrônica de varredura, espectroscopia de absorção no ultravioleta visível e espectroscopia de fotoluminescência.

As amostras foram caracterizadas por difração de raios $\mathrm{X}$ em difratômetro para amostras policristalinas XPert Pro MPD - PANalytical. Os ensaios foram realizados no intervalo angular de $10^{\circ}$ a $100^{\circ}$ e passo de varredura de $0,013^{\circ} \mathrm{min}^{-1}$ com radiação Cuk $\alpha(\lambda=1,540562 \AA)$, com filtro de níquel e monocromador. Os dados referentes aos parâmetros de rede e volume das celas unitárias foram calculados pelo método de Rietveld [35], com o programa GSAS [36] e a interface do EXPGUI [37]. Para modelar os picos foi utilizada a função pseudo-Voigt de Thomas-CoxHasting (TCHZ) modificada. O método de Rietveld consiste em um modelo teórico de ajuste de um difratograma (obtido por análise de pó) a um padrão de difração adequado, que permite a obtenção de informações da estrutura cristalina e informações analíticas dos materiais, empregando o método dos mínimos quadrados. Por meio do método de Rietveld torna-se possível determinar parâmetros da amostra, tais como parâmetros de rede, posições atômicas, fatores de 
vibração térmica, identificação de impurezas, e estimar o tamanho de grão da amostra. $\mathrm{O}$ método permite também a quantificação de múltiplas fases [38-40]. Foram refinados, neste trabalho, os seguintes parâmetros: (a) cela unitária e deslocamento de amostra; (b) largura dos picos de difração ajustados por uma pseudo-Voigt; (c) posição atômica do oxigênio; (d) parâmetros de deslocamento atômicos (parâmetro térmico). Para a determinação da contribuição instrumental na largura dos picos de difração, os parâmetros instrumentais foram determinados pelo refinamento da amostra padrão de $\mathrm{LaB}_{6}$ adquirida do National Institute of Standard Technology (NIST).

A análise por espectroscopia Raman foi feita em um equipamento Micro-Raman Confocal Bruker Senterra, com microscópio Olympus BX50, monocromador ligado a um CCD (Charged-Coupled Device), na região espectral de $85 \mathrm{~cm}^{-1}$ a $1000 \mathrm{~cm}^{-1}$. As análises foram feitas na temperatura ambiente, com um laser de $532 \mathrm{~nm}$ com potência de saída $10 \mathrm{~mW}$, com um tempo de integração de $10 \mathrm{~s}$.

As análises de espectrofotometria de absorção óptica na região do infravermelho foram feitas em um equipamento Bruker Vertex 70 na região entre $400 \mathrm{~cm}^{-1}$ a $1200 \mathrm{~cm}^{-1}$, utilizando a técnica das pastilhas de $\mathrm{KBr}$.

A morfologia dos cristais de $\mathrm{Ba}_{1-x} \mathrm{Ho}_{2 \times / 3} \mathrm{WO}_{4}$ foi investigada por microscopia eletrônica de varredura (Field Emission Gun - Scanning Electron Microscopy) em um TM3000 Hitachi operando a $15 \mathrm{kV}$. As amostras foram depositadas e fixadas ao porta-amostra com uma fita de carbono.

Os espectros de absorbância na região do UV-Vis foram obtidos em um espectrofotômetro UV-2600 Shimadzu, com janela de varredura de 800 a $200 \mathrm{~nm}$, com velocidade lenta de varredura.

Para realização das medidas de fotoluminescência, foi utilizado um laser de $\mathrm{Kr}+$ Innova 200 da Coherent na linha de $350,7 \mathrm{~nm}$, com potência de saída $\sim 500 \mathrm{~mW}$, sendo que a potência que incide sobre a amostra, após passar o feixe por diversos componentes ópticos (1 prisma, 4 espelhos, 2 lentes, chopper a $138 \mathrm{~Hz}$ e uma íris), estava em $\sim 14 \mathrm{~mW}$. A aquisição de dados foi feita em um PC com interface para comandar o motor de passo do monocromador e receber sinal do amplificador lock-in Stanford Research Systems SR530. O monocromador foi Thermo Jarrell Ash de $27 \mathrm{~cm}$ com torre de 3 grades de difração e o detector para a região visível uma fotomultiplicadora Hamamatsu R955 operando a $500 \mathrm{~V}$ e filtro passa alta L37.

\section{RESULTADOS E DISCUSSÃO}

As amostras de $\mathrm{Ba}_{1-x} \mathrm{Ho}_{2 \times 3} \mathrm{WO}_{4}$ foram caracterizadas por difração de raios $\mathrm{X}$ pelo método do pó. A Fig. 4 apresenta os difratogramas de raios $\mathrm{X}$ das amostras de $\mathrm{Ba}_{1-x} \mathrm{Ho}_{2 \times / 3} \mathrm{WO}_{4}$, que mostram que fases cristalinas intermediárias não são observadas nos difratogramas das amostras de $\mathrm{BaWO}_{4}$ puro e de $\mathrm{Ba}_{1-\mathrm{x}} \mathrm{Ho}_{2 \times 3} \mathrm{WO}_{4}$ (tungstato de bário dopado com hólmio), indicando a formação de uma única fase cristalina.

Com o programa X'Pert HighScore Plus (Versão 2.0.1

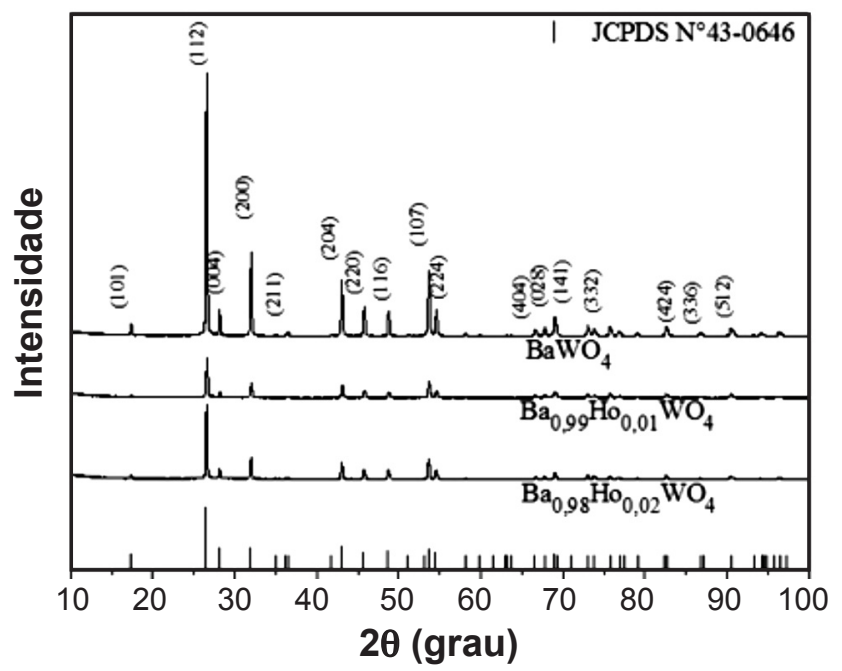

Figura 4: Difratogramas de raios $\mathrm{X}$ das amostras de $\mathrm{Ba}_{1-\mathrm{x}} \mathrm{Ho}_{2 \times / 3} \mathrm{WO}_{4}$. [Figure 4: X-ray diffraction patterns of the $\mathrm{Ba}_{1-x} \mathrm{Ho}_{2 \times / 3} \mathrm{WO}_{4}$ samples.]

Windows) foi feita a identificação dos picos com base nos arquivos JCPDS. Foi verificado que estes padrões de difração pertencem à estrutura tetragonal do tipo scheelita, com grupo espacial I41/, de acordo com o arquivo JCPDS 43-0646. O pico de maior intensidade, localizado entre 25 e $30^{\circ}$, corresponde ao plano cristalográfico (112) [41]. Foi observada significativa redução da intensidade dos picos, em especial deste, quando realizada a inserção de íons $\mathrm{Ho}^{3+}$ na estrutura, o que sugere uma diminuição da cristalinidade destes materiais no processo de dopagem.

Na Fig. 5 estão ilustrados os refinamentos pelo método de Rietveld para as amostras de $\mathrm{Ba}_{1-x} \mathrm{Ho}_{2 \times / 3} \mathrm{WO}_{4}$. Para as amostras dopadas com hólmio, abaixo de $20^{\circ}(2 \theta)$ há um indício de formação de fase amorfa nos respectivos perfis de difração, o que corrobora com a observação preliminar da diminuição da intensidade relativa dos picos. Na Tabela I, por sua vez, são apresentados os valores dos parâmetros de rede obtidos neste trabalho e em outros trabalhos da literatura.

Conforme pode ser verificado na Tabela II, os parâmetros de rede e volume da cela unitária obtidos neste trabalho para o $\mathrm{BaWO}_{4}$ são muito próximos dos valores descritos por outros trabalhos já publicados $[4,8,21]$ e também do arquivo JCPDS 43-0646 [41].

São apresentadas nas Tabelas III e IV as coordenadas atômicas das celas unitária de $\mathrm{Ba}_{1-\mathrm{x}} \mathrm{Ho}_{2 \times / 3} \mathrm{WO}_{4}$. Essas tabelas mostram que os átomos de $\mathrm{Ba}$, Ho e $\mathrm{W}$ permaneceram em suas posições características, enquanto as posições dos átomos de $\mathrm{O}$ tiveram grandes perturbações ao longo das coordenadas cartesianas $x, y$ e $z$ de cada cela unitária, ocasionando diferentes distorções nas ligações $\mathrm{Ba}-\mathrm{O}, \mathrm{Ho}^{-} \mathrm{O}$ e $\mathrm{W}-\mathrm{O}$ e consequentemente nos clusters correspondentes. Foram apresentados ainda os valores de dois parâmetros estatísticos calculados ao final de cada ciclo de refinamento que indicam a convergência destes. Estes índices foram o $\mathrm{R}_{\text {ponderado }}(w R p)$ e o "goodness of fit" (S). Os índices apresentados mostram que os refinamentos estruturais foram satisfatórios, tendo 
Tabela I - Dados comparativos dos parâmetros de rede e volume da cela unitária para os cristais de $\mathrm{Ba}_{1-\mathrm{x}} \mathrm{Ho}_{2 \times / 3} \mathrm{WO}_{4}$ obtidos neste trabalho e outros citados na literatura para $\mathrm{BaWO}_{4}$ sintetizado por diferentes metodologias.

[Table I - Comparative data between lattice parameters and volume of the unit cell for the $\mathrm{Ba}_{1-x} \mathrm{Ho}_{2 \times 3} \mathrm{WO}_{4}$ crystals obtained in this work and other ones cited in literature by different methods.]

\begin{tabular}{|c|c|c|c|c|c|c|}
\hline Método & $\begin{array}{l}{[\mathrm{T}]} \\
\left({ }^{\circ} \mathrm{C}\right)\end{array}$ & $\begin{array}{c}{[\mathrm{t}]} \\
(\mathrm{min})\end{array}$ & Parâmet & rede $(\AA)$ & $\begin{array}{l}{[\mathrm{V}]} \\
\left(\AA^{3}\right)\end{array}$ & Ref. \\
\hline $\mathrm{CP}$ & 25 & 20 & 5,619276 & 12,729916 & 401,963 & 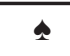 \\
\hline $\mathrm{CP}$ & 25 & 20 & 5,621922 & 12,73741 & 402,368 & $\square$ \\
\hline $\mathrm{CP}$ & 25 & 20 & 5,622471 & 12,733914 & 402,547 & \& \\
\hline $\mathrm{CP}$ & 25 & 2 & 5,60433 & 12,7338 & 399,949 & [8] \\
\hline $\begin{array}{c}\text { DLP } \\
\text { JCPDS }\end{array}$ & 800 & 240 & 5,60 & 12,62 & 396 & [4] \\
\hline 43-0646 & - & - & 5,6123 & 12,7059 & 400,21 & [41] \\
\hline
\end{tabular}

Tabela II - Coordenadas atômicas da cela unitária de $\mathrm{BaWO}_{4}$, conforme refinamento de Rietveld realizado neste trabalho. [Table II - Atomic coordinates of BaWO unit cell calculated by Rietveld refinement.]

\begin{tabular}{ccccccc}
\hline & & $\mathrm{BaWO}_{4}$ & & \multicolumn{3}{c}{ Parâmetros Estatísticos } \\
\hline Átomos & Posições de Wyckoff & $\mathrm{x}$ & $\mathrm{y}$ & $\mathrm{z}$ & \multirow{2}{*}{ wRp (\%) } & $\mathrm{S}$ \\
\cline { 1 - 5 } $\mathrm{Ba}$ & $4 b$ & 0 & 0,750 & 0,375 & & \multirow{2}{*}{8,13} \\
\cline { 1 - 5 } $\mathrm{W}$ & $4 a$ & 0 & 0,250 & 0,125 & \multirow{2}{*}{8,71} & \\
\cline { 1 - 5 } & $16 f$ & 0,114341 & 0,023670 & 0,201972 & & \\
\hline
\end{tabular}

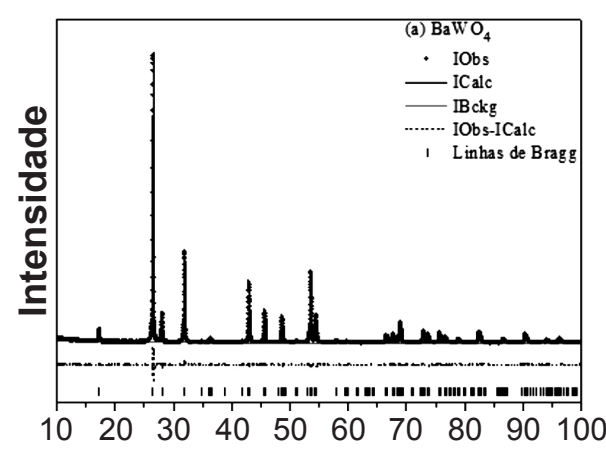
$2 \theta$ (grau)

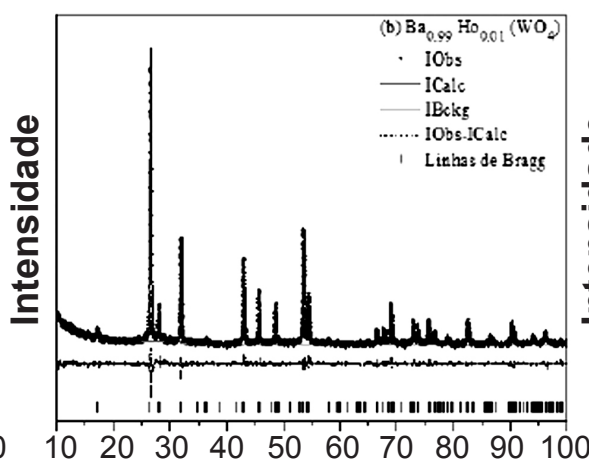

$2 \theta$ (grau)

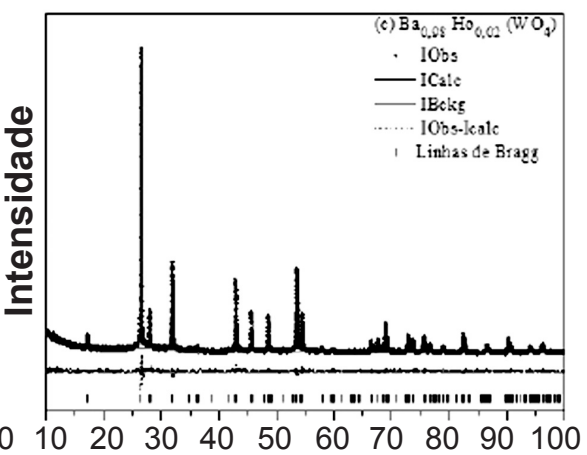

$2 \theta$ (grau)

Figura 5: Gráfico de refinamento de Rietveld das amostras obtidas neste trabalho: (a) $\mathrm{BaWO}_{4}$, (b) $\mathrm{Ba}_{0,99} \mathrm{Ho}_{0,01} \mathrm{WO}_{4}$ e (c) $\mathrm{Ba}_{0,98} \mathrm{Ho}_{0,02} \mathrm{WO}_{4}$. [Figure 5: Rietveld refinement plots of the samples obtained in this work: (a) $\mathrm{BaWO}_{4}$, (b) $\mathrm{Ba}_{0.99} \mathrm{Ho}_{0.01} \mathrm{WO}_{4}$ and (c) $\mathrm{Ba}_{0.98} \mathrm{Ho}_{0.02} \mathrm{WO}_{4}$.]

em vista que os valores de wRp encontrados estão abaixo de $10 \%$ e que os valores de $\mathrm{S}$ estão abaixo de 2 [42].

A determinação do tamanho do cristalito (TC) foi feita com a equação de Scherrer (Eq. A):

$$
\mathrm{TC}=\frac{\lambda \mathrm{K}}{\beta \cos \theta}
$$

na qual $\lambda$ é o comprimento de onda da fonte de raios $\mathrm{X}$ $(1,540562 \AA)$, k depende da geometria do cristalito (admitido como 0,9 para cristalitos esféricos), $\theta$ é o ângulo de Bragg e $\beta$ corresponde à largura à meia altura do pico de difração em radianos após descontada a largura instrumental pelo refinamento do padrão de $\mathrm{LaB}_{6}$, segundo a equação:

$$
\beta_{\mathrm{hkl}}=\sqrt{\beta_{\mathrm{exp}}^{2}-\beta_{\mathrm{inst}}^{2}}
$$

na qual $\beta_{\text {exp }}$ é a largura experimental da amostra e $\beta_{\text {inst }}$ corresponde à largura instrumental $[43,44]$. Os tamanhos de cristalito médio (TC) das amostras de $\mathrm{Ba}_{1-\mathrm{x}} \mathrm{Ho}_{1-\mathrm{x}} \mathrm{WO}_{4}$, foram determinados e comparados com valores obtidos por meio do refinamento de Rietveld, ambos apresentados na Tabela IV. Houve nítida discrepância entre estes valores, tendo em 
Tabela III - Coordenadas atômicas das células unitárias de $\mathrm{Ba}_{1-x} \mathrm{Ho}_{2 \times / 3} \mathrm{WO}_{4}$, conforme refinamento de Rietveld. [Table III - Atomic coordinates of $\mathrm{Ba}_{1-x} \mathrm{Ho}_{2 \times / 3} \mathrm{WO}_{4}$ unit cell calculated by Rietveld refinement.]

\begin{tabular}{|c|c|c|c|c|c|c|}
\hline \multicolumn{5}{|c|}{$\mathrm{Ba}_{0,99} \mathrm{Ho}_{0,01}\left(\mathrm{WO}_{4}\right)$} & \multicolumn{2}{|c|}{ Parâmetros Estatísticos } \\
\hline Átomos & $\begin{array}{c}\text { Posições de } \\
\text { Wyckoff }\end{array}$ & $\mathrm{x}$ & $\mathrm{y}$ & $\mathrm{z}$ & wRp (\%) & S \\
\hline $\mathrm{Ba}$ & $4 b$ & 0 & 0,750 & 0,375 & \multirow{4}{*}{8,52} & \multirow{4}{*}{1,16} \\
\hline Ho & $4 b$ & 0 & 0,750 & 0,375 & & \\
\hline $\mathrm{W}$ & $4 a$ & 0 & 0,250 & 0,125 & & \\
\hline $\mathrm{O}$ & $16 f$ & 0,135146 & $-0,006014$ & 0,202936 & & \\
\hline \multicolumn{5}{|c|}{$\mathrm{Ba}_{0,98} \mathrm{Ho}_{0,02}\left(\mathrm{WO}_{4}\right)$} & \multicolumn{2}{|c|}{ Parâmetros Estatísticos } \\
\hline Átomos & $\begin{array}{l}\text { Posições de } \\
\text { Wyckoff }\end{array}$ & $\mathrm{x}$ & $\mathrm{y}$ & $\mathrm{z}$ & wRp (\%) & S \\
\hline $\mathrm{Ba}$ & $4 b$ & 0 & 0,750 & 0,375 & \multirow{4}{*}{8,22} & \multirow{4}{*}{1,19} \\
\hline Ho & $4 b$ & 0 & 0,750 & 0,375 & & \\
\hline $\mathrm{W}$ & $4 a$ & 0 & 0,250 & 0,125 & & \\
\hline $\mathrm{O}$ & $16 f$ & 0,125724 & 0,012826 & 0,196970 & & \\
\hline
\end{tabular}

vista que a equação de Scherrer não considera a contribuição da microdeformação para as larguras dos picos de difração, às quais foram refinadas considerando este parâmetro [43, 44].

Tungstatos com estrutura tetragonal do tipo scheelita exibem 26 modos vibracionais distintos, de acordo com a Teoria de Grupos, representados pela equação abaixo:

$$
\Gamma_{\text {(Raman+Infravermelho) }}=3 A_{g}+5 A_{u}+5 B_{g}+3 B_{u}+5 E_{g}+5 E_{u}
$$

Os modos $A_{g}, B_{g}$ e $E_{g}$ são ativos no Raman. Os modos $A$ e $B$ são não-degenerados, enquanto os modos $E$ são duplamente degenerados. Os índices " $g$ e $u$ " indicam operações de simetria correspondentes à inversão do centro simétrico dos cristais de $\mathrm{BaWO}_{4}$. Os modos $A_{u}$ e $B_{u}$ correspondem à frequência zero dos modos acústicos, enquanto os demais consistem em modos ópticos. Há 13 modos vibracionais ativos no Raman esperados para este material, conforme a equação abaixo $[8,42]$.

$$
\Gamma_{(\text {Raman) }}=3 A_{g}+5 B_{g}+5 E_{g}
$$

Há dois tipos de modos vibracionais observados para os tungstatos em geral: os modos externos e internos. Os modos externos estão relacionados às vibrações observadas nos clusters $\left[\mathrm{BaO}_{8}\right]$. Os modos internos, por sua vez, estão relacionados às vibrações nos clusters do formador de rede, ou seja, $\left[\mathrm{WO}_{4}\right]$, sendo que o $\mathrm{W}$ é considerado um centro de massa estacionário [8].

Nos espectros vibracionais na região do infravermelho, dois modos acústicos, $1 A_{u}$ e $1 E_{u^{\prime}}$, são inativos e os modos ópticos $B_{u}$ são proibidos. Dessa forma, restam 8 modos vibracionais ativos esperados no infravermelho:

$$
\Gamma_{\text {(Infravermelho) }}=4 A_{u}+4 E_{u}
$$

A Fig. 6 ilustra os espectros Raman na região de $85 \mathrm{~cm}^{-1}$ a $1000 \mathrm{~cm}^{-1}$ para os óxidos de fórmula genérica $\mathrm{Ba}_{1-x} \mathrm{Ho}_{2 \times / 3} \mathrm{WO}_{4}$ sintetizados pelo método de coprecipitação.

Dez modos vibracionais foram identificados para todas as amostras. Como observado nessa figura, os picos principais apresentaram-se bem definidos, intensos e estreitos, sugerindo que estes óxidos apresentam ordenamento a curto alcance, com uma forte interação entre os clusters que provêm do estiramento simétrico $(\leftarrow \mathrm{O} \leftarrow \mathrm{W} \rightarrow \mathrm{O} \rightarrow)$. Utilizando o software PeakFit V4 (Windows), cada espectro foi ajustado e foram identificados os modos vibracionais apresentados nas Tabelas VI e VII, os quais estão relacionados à estrutura tetragonal scheelita e calculadas as respectivas larguras à meia altura. Dois modos vibracionais $\left(1 B_{g}\right.$ e $\left.1 E_{g}\right)$ não foram detectados por ocorrerem em um deslocamento Raman menor que $85 \mathrm{~cm}^{-1}$ (limite inferior do intervalo de aquisição dos dados) e um modo $B_{g} \mathrm{em} \sim 334 \mathrm{~cm}^{-1}$ não aparece por estar sobreposto ao pico em $\sim 354 \mathrm{~cm}^{-1}[8]$.

$\mathrm{O}$ aumento da concentração de íons $\mathrm{Ho}^{3+}$ na rede do sistema $\mathrm{Ba}_{1-\mathrm{x}} \mathrm{Ho}_{2 \times / 3} \mathrm{WO}_{4}$ provocou uma tendência geral de alargamento dos picos Raman na região do modificador de rede (picos 3 e 4) e na região do formador de rede $\left[\mathrm{WO}_{4}\right]$ (demais modos). A largura à meia altura pode estar associada

Tabela IV - Tamanhos de cristalito (TC) obtidos pelos dados de refinamento Rietveld e pela equação de Scherrer.

[Table IV - Crystallite size (CT) obtained by Rietveld refinement and Scherrer equation.]

\begin{tabular}{ccc}
\hline Amostra & $\begin{array}{c}\text { TC Rietveld } \\
(\mathrm{nm})\end{array}$ & $\begin{array}{c}\text { TC Scherrer } \\
(\mathrm{nm})\end{array}$ \\
\hline $\mathrm{BaWO}_{4}$ & 100 & 88,6 \\
$\mathrm{Ba}_{0,01} \mathrm{Ho}_{0,99} \mathrm{WO}_{4}$ & 80 & 84,5 \\
$\mathrm{Ba}_{0,02} \mathrm{Ho}_{0,98} \mathrm{WO}_{4}$ & 95 & 114,9 \\
\hline
\end{tabular}




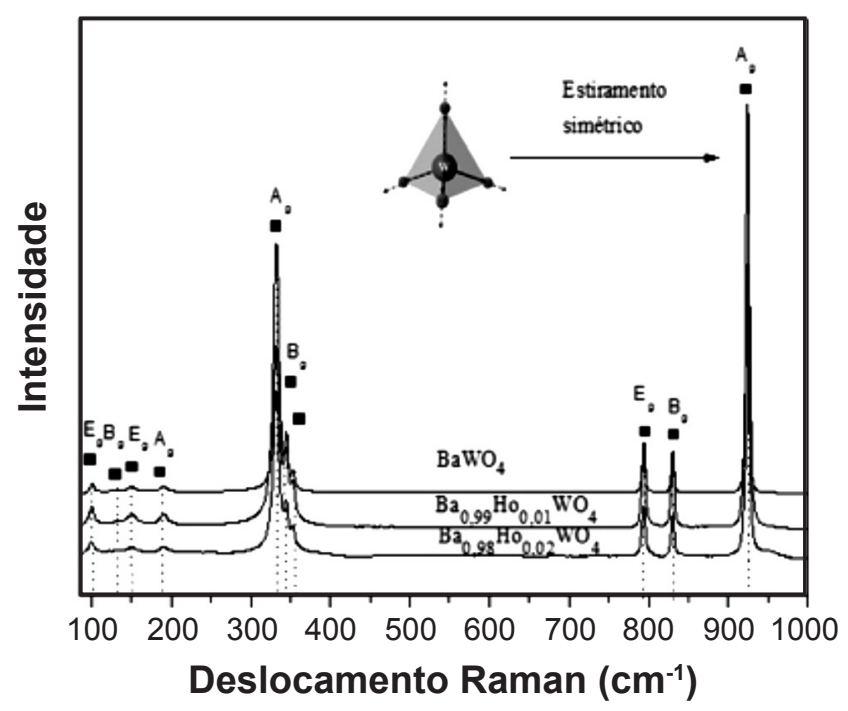

Figura 6: Espectros Raman na faixa de 85 a $1000 \mathrm{~cm}^{-1}$ de $\mathrm{Ba}_{1-\mathrm{x}} \mathrm{Ho}_{2 \times / 3} \mathrm{WO}_{4}, \mathrm{x}=0,0,01$ e 0,02 , obtidos por coprecipitação à temperatura ambiente.

[Figure 6: Raman spectra in the range from 85 to $1000 \mathrm{~cm}^{-1}$ of $\mathrm{Ba}_{1-x} \mathrm{Ho}_{2 \times / 3} \mathrm{WO}_{4}, \mathrm{x}=0,0.01$ and 0.02, obtained by coprecipitation at room temperature.]

à desordem a curto alcance, o que justifica que, na medida em que são inseridos íons dopantes na matriz de $\mathrm{BaWO}_{4}$ se verifica um alargamento dos picos Raman [45]. Pequenos deslocamentos dos picos nos espectros Raman foram observados conforme a Tabela $\mathrm{V}$ e podem ser correlacionados aos seguintes fatores: distribuição de tamanho dos grãos, distorções das ligações dos clusters $(\mathrm{O}-\mathrm{W}-\mathrm{O}) /(\mathrm{O}-\mathrm{Ba}-\mathrm{O})$, forças de interação envolvendo os clusters $\left[\mathrm{WO}_{4}\right]-\left[\mathrm{BaO}_{8}\right]-$ $\left[\mathrm{WO}_{4}\right]$ e desordem estrutural do retículo cristalino a curto alcance [8, 42].

$\mathrm{Na}$ Tabela VI são apresentadas as atribuições dos principais modos ativos Raman para os pós de $\mathrm{BaWO}_{4}$. Os modos de vibração de maior energia, conforme a Tabela, referem-se aos modos simétricos e assimétricos de estiramento das ligações $\mathrm{O}-\mathrm{W}-\mathrm{O}$. Os modos menos energéticos, por sua vez, correspondem aos modos de torção entre $\mathrm{W}-\mathrm{O}$ e $\mathrm{Ba}-\mathrm{O}[46]$.

A Fig. 7 mostra os espectros de infravermelho (FT-IR) para os pós cerâmicos $\mathrm{Ba}_{1-\mathrm{x}} \mathrm{Ho}_{2 \mathrm{x} / 3} \mathrm{WO}_{4}$ sintetizados a $25^{\circ} \mathrm{C}$.

Como anteriormente discutido, de acordo com a teoria de grupos, são esperados 8 modos ativos para estes materiais na região do IR, entretanto apenas dois modos vibracionais foram detectados, uma vez que a aquisição dos espectros de FT-IR foi limitada à faixa de $400 \mathrm{~cm}^{-1}$ a $4000 \mathrm{~cm}^{-1}$, devido às configurações do equipamento e ao método empregado (pastilhas de $\mathrm{KBr})$. Estes modos $\left(1 A_{u}\right.$ e $\left.1 E_{u}\right)$ aparecem em todas as amostras como fortes bandas de absorção às quais correspondem aos modos de absorção internos dos clusters $\left[\mathrm{WO}_{4}\right]$, de natureza assimétrica, do tipo $(\rightarrow \mathrm{O} \rightarrow \mathrm{W} \rightarrow \mathrm{O})$. Os demais modos, associados ao estiramento simétrico dos clusters formadores de rede, assim como os modos de deformação, encontram-se abaixo de $400 \mathrm{~cm}^{-1}$ (região do infravermelho distante) e por esse motivo não foram identificados nos espectros [8]. Pela análise dos modos no infravermelho, calculados por intermédio do programa PeakFit V4, e apresentados na Tabela VII, pode-se constatar deslocamentos destes estiramentos assimétricos para as amostras. Este comportamento pode estar associado entre outros fatores, a distorções dos clusters $\left[\mathrm{WO}_{4}\right]$ na rede e à substituição dos clusters $\left[\mathrm{BaO}_{8}\right]$ por clusters $\left[\mathrm{HoO}_{8}\right]$ que influenciam de forma considerável a vizinhança formada pelos clusters [ $\left.\mathrm{WO}_{4}\right]$ [8]. Nos espectros de IR das amostras dopadas foi observada uma banda próxima a $924 \mathrm{~cm}^{-1}$, cuja intensidade aumentou com o aumento da concentração de íons $\mathrm{Ho}^{3+}$. Conforme discutido anteriormente, nos espectros Raman

Tabela V - Resultados comparativos entre os modos ativos no Raman de $\mathrm{Ba}_{1-\mathrm{x}} \mathrm{Ho}_{2 \times / 3} \mathrm{WO}_{4}$ e valores correspondentes de largura à meia altura.

[Table V-Comparative results between Raman active modes of $\mathrm{Ba}{ }_{1-x} \mathrm{Ho}_{2 x / 3} \mathrm{WO}_{4}$ and corresponding full-width at half maximum values.]

\begin{tabular}{cccccccc}
\hline \multirow{2}{*}{ Pico } & \multicolumn{3}{c}{$\mathrm{BaWO}_{4}$} & \multicolumn{2}{c}{$\mathrm{Ba}_{0,99} \mathrm{Ho}_{0,01} \mathrm{WO}_{4}$} & \multicolumn{2}{c}{$\mathrm{Ba}_{0,98} \mathrm{Ho}_{0,02} \mathrm{WO}_{4}$} \\
\cline { 2 - 8 } & Modo & Modo & FWHM(1) & Modo & FWHM & Modo & FWHM \\
\hline 1 & $\mathrm{E}_{\mathrm{g}}$ & 100,518 & 6,95931 & 99,8369 & 8,86593 & 99,6836 & 9,56499 \\
2 & $\mathrm{~B}_{\mathrm{g}}$ & 132,256 & 7,86577 & 130,996 & 9,1025 & 129,866 & 23,4674 \\
3 & $\mathrm{~A}_{\mathrm{g}}$ & 149,493 & 11,8012 & 150,112 & 17,3226 & 150,238 & 15,6345 \\
4 & $\mathrm{E}_{\mathrm{g}}$ & 190,17 & 11,4756 & 190,553 & 15,8125 & 191,688 & 19,6867 \\
5 & $\mathrm{~A}_{\mathrm{g}}$ & 331,887 & 7,97401 & 332,013 & 9,34961 & 331,831 & 9,34393 \\
6 & $\mathrm{~B}_{\mathrm{g}}$ & 344,604 & 5,34911 & 344,753 & 6,38365 & 344,936 & 6,44457 \\
7 & $\mathrm{E}_{\mathrm{g}}$ & 352,667 & 6,93862 & 353,748 & 6,87067 & 353,593 & 6,40221 \\
8 & $\mathrm{E}_{\mathrm{g}}$ & 794,152 & 4,92525 & 794,177 & 6,18291 & 794,012 & 5,91593 \\
9 & $\mathrm{~B}_{\mathrm{g}}$ & 830,36 & 4,60073 & 830,445 & 5,76723 & 830,386 & 5,2212 \\
10 & $\mathrm{~A}_{\mathrm{g}}$ & 924,655 & 4,87168 & 924,836 & 6,01646 & 924,686 & 5,90219 \\
\hline
\end{tabular}

FWHM (Full Width at Half Maximum) = largura à meia altura. 
Tabela VI - Atribuições dos principais modos ativos Raman para cristais de $\mathrm{BaWO}_{4}$.

[Table VI - Main Raman active modes for $\mathrm{BaWO}_{4}$ crystals.]

\begin{tabular}{cl}
$\begin{array}{c}\text { Deslocamento } \\
\text { Raman }\left(\mathrm{cm}^{-1}\right)\end{array}$ & \multicolumn{1}{c}{ modos ativos Raman } \\
\hline $100,518\left(E_{g}\right)$ & Modos livres de vibração para o $\mathrm{WO}_{4}$ \\
$132,256\left(B_{g}\right)$ & Modo translacional da rede \\
$149,493\left(E_{g}\right)$ & Modo de torção Ba-O \\
$190,17\left(A_{g}\right)$ & Modo de torção Ba-O \\
$331,887\left(A_{g}\right)$ & Modos de torção simétricos O-W-O \\
$344,604\left(B_{g}\right)$ & Modos de torção assimétricos O-W-O \\
$352,667\left(E_{g}\right)$ & Modos de torção assimétricos O-W-O \\
$794,152\left(E_{g}\right)$ & Estiramento assimétrico O-W-O \\
$830,36\left(B_{g}\right)$ & Estiramento assimétrico O-W-O \\
$924,655\left(A_{g}\right)$ & Estiramento simétrico O-W-O \\
\hline
\end{tabular}

Fonte: Adaptado de [46].

Tabela VII - Atribuições dos principais modos ativos no infravermelho para cristais de $\mathrm{Ba}_{1-} \mathrm{xHo}_{2 \times / 3} \mathrm{WO}_{4}$.

[Table VII - Main IR active modes for $\mathrm{Ba}_{1} \times \mathrm{Ho}_{2 \times / 3} \mathrm{WO}_{4}$ crystals.]

\begin{tabular}{cll}
\hline Amostra & $\begin{array}{c}\text { Números de } \\
\text { onda }\left(\mathrm{cm}^{-1}\right)\end{array}$ & \multicolumn{1}{c}{$\begin{array}{c}\text { Modos Ativos } \\
\text { Infravermelho }\end{array}$} \\
\hline $\mathrm{BaWO}_{4}$ & $779,36\left(E_{u}\right)$ & Estiramentos assimétricos \\
& $855,89\left(A_{u}\right) \rightarrow \mathrm{O} \rightarrow \mathrm{W} \rightarrow \mathrm{O}$
\end{tabular}

destes materiais, esta região corresponde às vibrações simétricas dos clusters $\left[\mathrm{WO}_{4}\right]$. Como a técnica de infravermelho permite a observação apenas de vibrações assimétricas [47], a ocorrência desta banda corrobora com a hipótese de os clusters $\left[\mathrm{WO}_{4}\right]$ terem sofrido distorções significativas com a adição de íons hólmio, gerando uma quebra de simetria.

A morfologia das amostras de $\mathrm{Ba}_{1-x} \mathrm{Ho}_{2 \times / 3} \mathrm{WO}_{4}(\mathrm{x}=0$, 0,01 e 0,02 ) foi investigada empregando-se a técnica de microscopia eletrônica de varredura acoplada à espectroscopia de energia dispersiva de raios X. As imagens da Fig. 8 (a-f) mostram as micrografias obtidas.

Para os pós de $\mathrm{BaWO}_{4}$, Fig. 8a, foram obtidas partículas octaédricas irregulares, similares a "grãos de arroz" (rice -like), resultado que difere da morfologia reportada [8], na qual obtiveram grãos de $\mathrm{BaWO}_{4}$ semelhantes a "bombons" ou "balas", utilizando o método de coprecipitação à temperatura ambiente. Essa divergência nas morfologias pode estar associada às diferentes fontes precursoras de Ba empregadas, haja visto que neste trabalho foi empregado cloreto, enquanto naquele foi utilizado o nitrato.

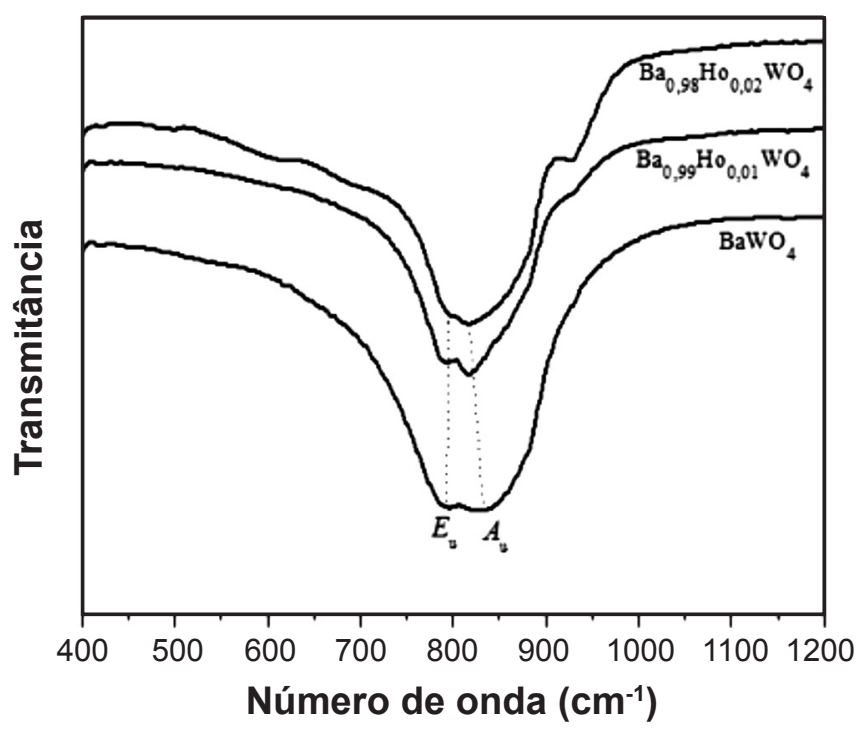

Figura 7: Espectros de Infravermelho com Transformadas de Fourier na faixa de 400 a $1200 \mathrm{~cm}^{-1}$ dos óxidos $\mathrm{Ba}_{1-\mathrm{x}} \mathrm{Ho}_{2 \mathrm{x} / 3} \mathrm{WO}_{4}, \mathrm{x}=0$, 0,01 e 0,02 , obtidos por coprecipitação à temperatura ambiente.

[Figure 7: FTIR spectra in the range from 400 to $1200 \mathrm{~cm}^{-1}$ of the $\mathrm{Ba}_{1-x} \mathrm{Ho}_{2 \times / 3} \mathrm{WO}_{4}, x=0.0 .01$ and 0.02 , obtained by coprecipitation at room temperature.]

Observando-se as Figs. 8b e 8c para as amostras dopadas com íons $\mathrm{Ho}^{3+}$, é constatada diminuição da cristalinidade ou amorfização do material em relação ao $\mathrm{BaWO}_{4}$ puro e distribuição granulométrica irregular. Este resultado corrobora com a análise dos dados de difração, espectros Raman e FT-IR. Quanto ao tamanho médio dos grãos, a Tabela VIII apresenta as faixas de menor e maior tamanho dos grãos investigados. Como observado, há um aumento do comprimento e largura médios dos grãos, com o aumento da concentração do dopante.

As Figs. 9a-c ilustram a dependência dos espectros de absorbância na região do UV-Vis com a concentração nominal de íons $\mathrm{Ho}^{3+}$. Os valores do gap de banda óptica foram calculados por meio da metodologia proposta por Wood e Tauc [48], na qual a relação entre a energia da banda gap, a absorbância e a energia dos fótons pode ser expressa pela seguinte proporcionalidade:

$$
\mathrm{h} v \alpha \propto\left(\mathrm{h} v-E_{\text {gap }}\right)^{2}
$$

na qual $\alpha$ é a absorbância, $h$ a constante de Planck, $v$ é a frequência e $E_{\text {gap }}$ corresponde à energia do gap da banda.

Pela análise das Figs. 9a-c, pode-se inferir que a inserção de íons $\mathrm{Ho}^{3+}$ à estrutura do $\mathrm{Ba}_{1-x} \mathrm{Ho}_{2 \times / 3} \mathrm{WO}_{4}$ provoca uma redução significativa no valor de $E_{\text {gap }}$. Este resultado indica que os íons $\mathrm{Ho}^{3+}$ induzem a formação de novos estados eletrônicos intermediários dentro do gap óptico do $\mathrm{BaWO}_{4}$, uma vez que os íons $\mathrm{Ho}^{3+}$ apresentam orbitais $4 f$ enquanto os íons $\mathrm{Ba}^{2+}$ apresentam orbitais $6 s$ na banda de valência.

A Fig. 10 ilustra os espectros de PL dos pós de $\mathrm{Ba}_{1-\mathrm{x}} \mathrm{Ho}_{2 \times / 3} \mathrm{WO}_{4}(\mathrm{com} \mathrm{x}=0,0,01$ e 0,02$)$ obtidos por coprecipitação, sob excitação de $350,7 \mathrm{~nm}$.

$\mathrm{O}$ espectro da amostra de $\mathrm{BaWO}_{4}$ puro apresenta-se na 

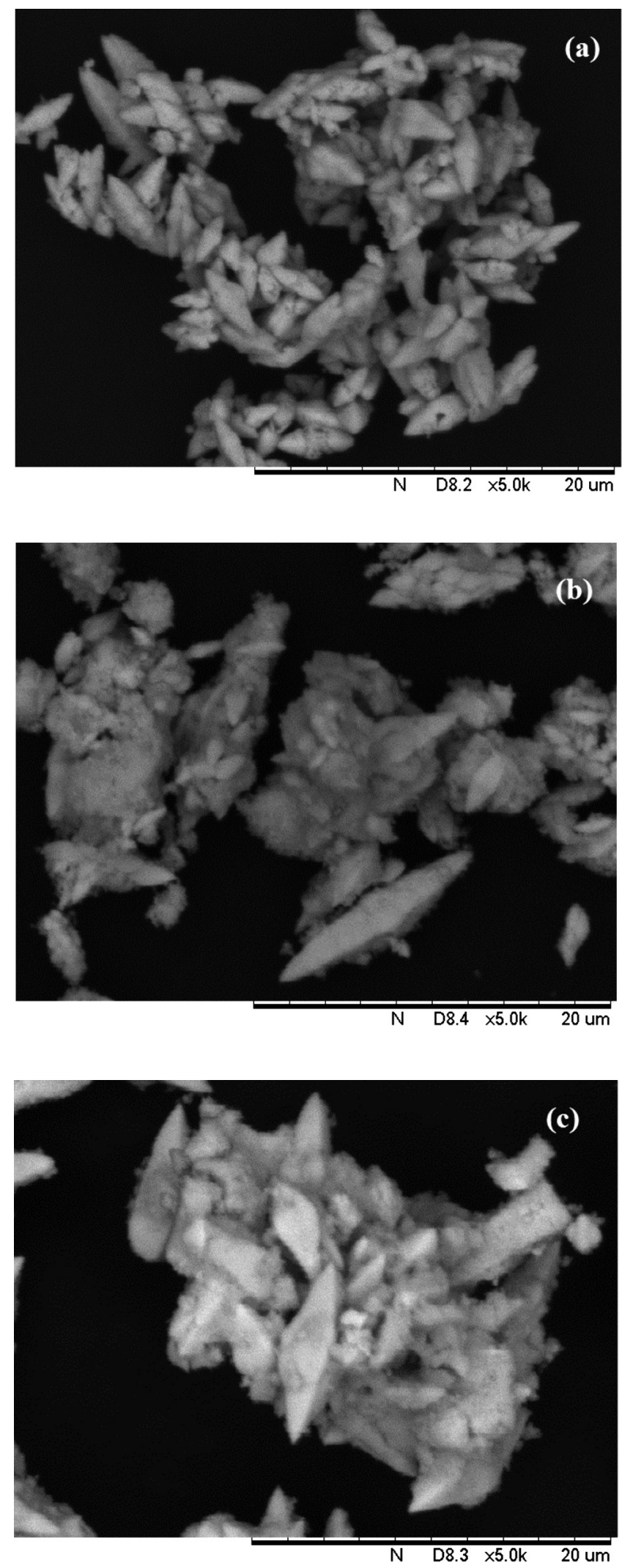

Figura 8: Imagens de microscopia eletrônica de varredura das amostras sintetizadas por coprecipitação à temperatura ambiente (a) $\mathrm{BaWO}_{4}$, (b) $\mathrm{Ba}_{0,99} \mathrm{Ho}_{0,01} \mathrm{WO}_{4}$ e (c) $\mathrm{Ba}_{0,98} \mathrm{Ho}_{0,02} \mathrm{WO}_{4}$.

[Figure 8: SEM images of the samples obtained by coprecipitation at room temperature: (a) $\mathrm{BaWO}_{4}$, (b) $\mathrm{Ba}_{0.99} \mathrm{Ho}_{0.01} \mathrm{WO}_{4}$ and (c) $\left.\mathrm{Ba}_{0.98} \mathrm{Ho}_{0.02} \mathrm{WO}_{4}.\right]$
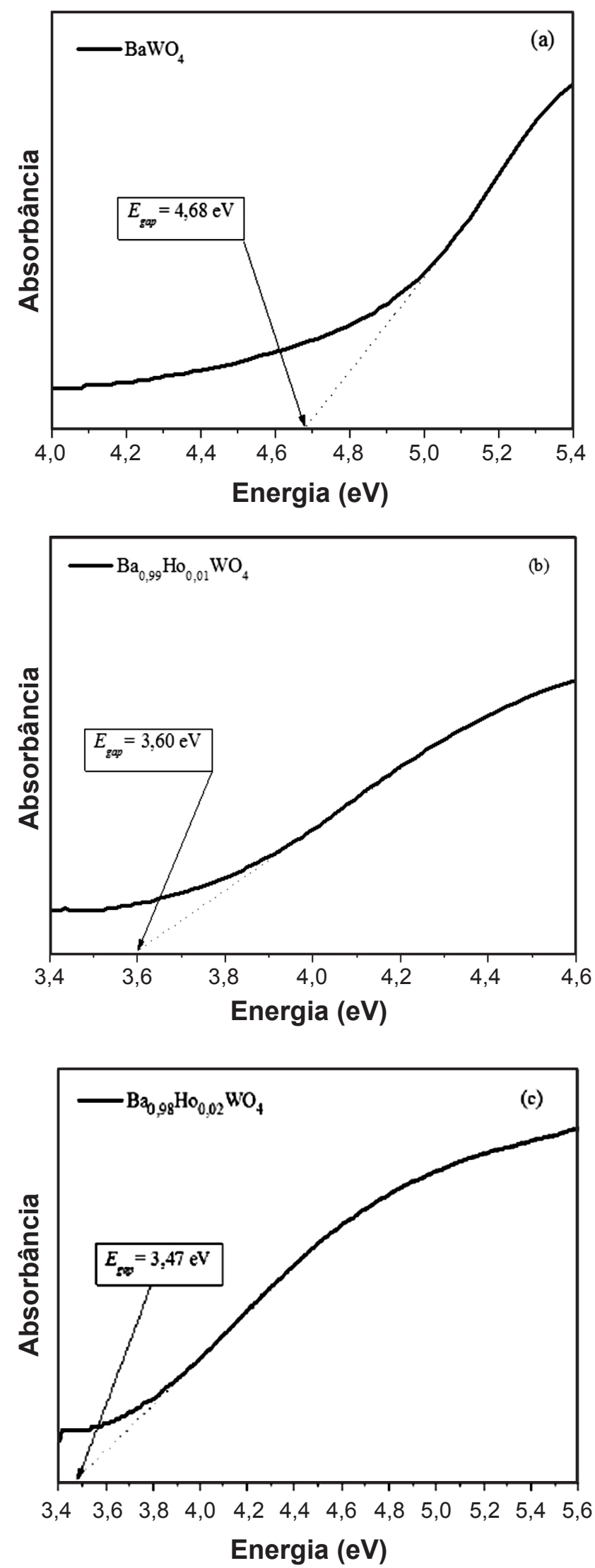

Figura 9: Espectros de absorbância para os pós de $\mathrm{Ba}_{1-\mathrm{x}} \mathrm{Ho}_{2 \times / 3} \mathrm{WO}_{4}$ obtidos por coprecipitação.

[Figure 9: UV vis absorbance spectra of the $\mathrm{Ba}_{1-x} \mathrm{Ho}_{2 \times / 3} \mathrm{WO}_{4}$ powders obtained by coprecipitation.] 
Tabela VIII - Comprimento e largura média dos grãos. [Table VIII - Average length and width of the grains.]

\begin{tabular}{ccccc}
\hline Amostra & $\begin{array}{c}\text { Intervalo de com- } \\
\text { primentos }(\mu \mathrm{m})\end{array}$ & $\begin{array}{c}\text { Comprimento médio } \\
(\mu \mathrm{m})\end{array}$ & $\begin{array}{c}\text { Intervalo de larguras } \\
(\mu \mathrm{m})\end{array}$ & $\begin{array}{c}\text { Largura média } \\
(\mu \mathrm{m})\end{array}$ \\
\hline $\mathrm{BaWO}_{4}$ & $1,764-7,489$ & 3,927 & $1,021-2,218$ & 1,577 \\
$\mathrm{Ba}_{0,99} \mathrm{Ho}_{0,01} \mathrm{WO}_{4}$ & $3,754-7,414$ & 5,683 & $1,404-3,018$ & 1,862 \\
$\mathrm{Ba}_{0,98} \mathrm{Ho}_{0,02} \mathrm{WO}_{4}$ & $5,226-12,305$ & 8,578 & $2,134-4,807$ & 3,082 \\
\hline
\end{tabular}

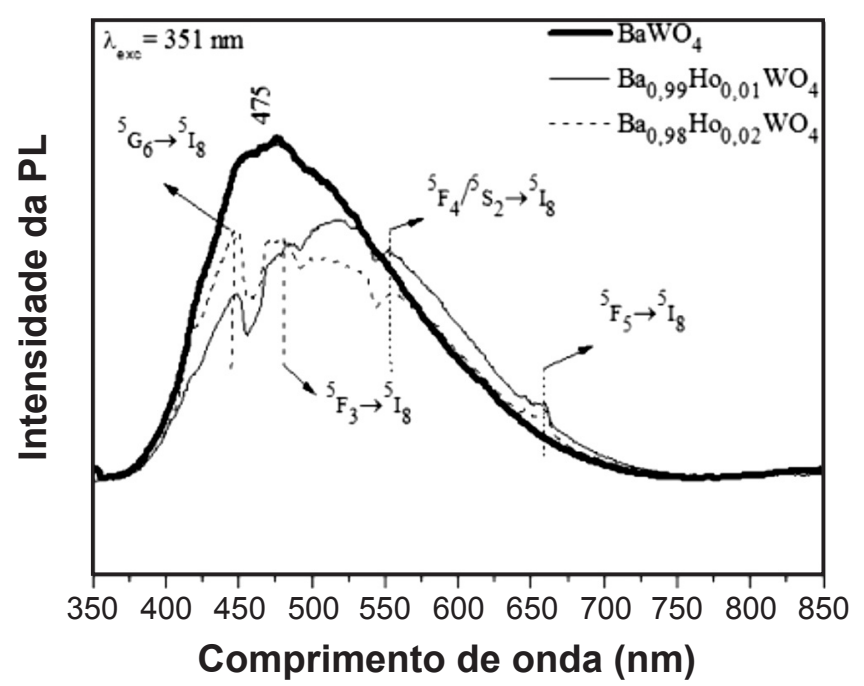

Figura 10: Espectros de emissão dos pós de $\mathrm{Ba}_{1-x} \mathrm{Ho}_{2 \times / 3} \mathrm{WO}_{4}$ obtidos por coprecipitação $\left(\lambda_{\text {exc }}=350,7 \mathrm{~nm}\right)$.

[Figure 10: Emission spectra of the $\mathrm{Ba}_{1-x} \mathrm{Ho}_{2 \times / 3} \mathrm{WO}_{4}$ powders obtained by coprecipitation $\left(\lambda_{\text {exc }}=350.7 \mathrm{~nm}\right)$.]

forma de uma banda larga centrada em $475 \mathrm{~nm}$ (emissão nas regiões do azul e verde). Esta banda no espectro de fotoluminescência está associada a significativo grau de desordem na estrutura do material [24]. Em contrapartida, as análises dos resultados de difração de raios $\mathrm{X}$ e dos espectros Raman comprovam que estes materiais apresentaram ordenamento cristalino a curto e a longo alcance. Neste caso, esta banda larga corresponde à transferência de cargas (permitidas por spin e Laporte) entre os orbitais $2 p$ do oxigênio e os orbitais $5 \mathrm{~d}$ dos íons $\mathrm{W}^{6+}\left(\mathrm{O}^{2-} \rightarrow \mathrm{W}^{6+}\right)$ nos clusters $\left[\mathrm{WO}_{4}\right][21]$.

Analisando os espectros dos pós dopados com quantidades nominais de 1 e $2 \%$ de íons $\mathrm{Ho}^{3+}$, claramente percebe-se uma redução da intensidade da luminescência, quando há substituição de íons $\mathrm{Ba}^{2+}$ por íons $\mathrm{Ho}^{3+}$ na estrutura cristalina. Este comportamento pode ser explicado, devido à formação de vacâncias de $\mathrm{Ba}^{2+}\left(\mathrm{V}_{\mathrm{Ba}}{ }^{\prime}\right)$ nos clusters $\left[\mathrm{BaO}_{8}\right]$ e complexas vacâncias de oxigênio às quais podem ser neutras $\left(\mathrm{V}^{\mathrm{x}}{ }_{\mathrm{O}}\right)$, isoladamente ionizadas $\left(\mathrm{V}^{*}{ }_{\mathrm{O}}\right)$ e duplamente ionizadas $\left(\mathrm{V}^{*}{ }_{\mathrm{O}}\right)$. Estas vacâncias buscam estabilizar-se por mecanismos de compensação de cargas em que $\mathrm{V}^{\mathrm{x}}{ }_{0}$ podem doar ou capturar até dois elétrons, $\mathrm{V}^{\cdot}$ podem capturar ou doar apenas um elétron e $\mathrm{V}^{*}{ }_{\mathrm{O}}$ não são capazes de doar, mas apenas de receber dois elétrons. Estas vacâncias produzem defeitos na estrutura cristalina do material
[8]. Outra explicação para esta redução da intensidade da luminescência para as amostras dopadas encontra-se no fato de que, a inserção de íons $\mathrm{Ho}^{3+}$ na matriz de $\mathrm{BaWO}_{4}$, consiste em um mecanismo de excitação dos íons $\mathrm{Ho}^{3+}$ por um estado excitado de um ligante. Nesse caso, a energia oriunda é da transferência de cargas entre orbitais $2 p$ dos ligantes $\mathrm{O}^{2-}$ e os orbitais $5 \mathrm{~d}$ dos íons $\mathrm{W}^{6+}$. Com isso, grande parte da energia intensa emitida pela transição $\mathrm{O}^{2-} \rightarrow \mathrm{W}^{6+}$ é transferida para excitação indireta dos íons $\mathrm{Ho}^{3+}$ produzindo as transições $f-f$ características destes íons, as quais são proibidas por Laporte e, portanto, requerem fontes de radiação intensas, devido suas intensidades relativamente baixas [49]. Além da redução da intensidade da luminescência, foram identificadas para a amostra dopada com $1 \%$ de $\mathrm{Ho}^{3+}$, algumas transições características dos íons hólmio em 448 nm, 488 nm, 550 nm e $657 \mathrm{~nm}$, às quais correspondem aos decaimentos ${ }^{5} \mathrm{G}_{6} \rightarrow{ }^{5} \mathrm{I}_{8}$, ${ }^{5} \mathrm{~F}_{3} \rightarrow{ }^{5} \mathrm{I}_{8},{ }^{5} \mathrm{~F}_{4} /{ }^{5} \mathrm{~S}_{2} \rightarrow{ }^{5} \mathrm{I}_{8} \mathrm{e}^{5} \mathrm{~F}_{5} \rightarrow{ }^{5} \mathrm{I}_{8}$, respectivamente [50-52].

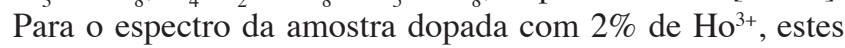
comprimentos de onda sofreram pequenos deslocamentos e correspondem a 448, 481, 554 e $659 \mathrm{~nm}$, respectivamente. A presença de transições características dos íons $\mathrm{Ho}^{3+}$ na estrutura destes materiais sustenta a hipótese de que a incorporação de íons $\mathrm{Ho}^{3+}$ na estrutura do $\mathrm{BaWO}_{4}$ induz a formação de níveis intermediários no interior do gap.

Uma interessante observação acerca do comportamento da fotoluminescência destes materiais é que, com o aumento da concentração de íons $\mathrm{Ho}^{3+}$ incorporados, houve um aumento da intensidade luminescente de ${ }^{5} \mathrm{G}_{6} \rightarrow{ }^{5} \mathrm{I}_{8}$ e ${ }^{5} \mathrm{~F}_{3} \rightarrow$ ${ }^{5} \mathrm{I}_{8}$ (às quais estão associadas a emissões na região do azul) e redução da intensidade luminescente nas regiões do verde e do vermelho correspondentes às transições ${ }^{5} \mathrm{~F}_{4} / 5 \mathrm{~S}_{2} \rightarrow{ }^{5} \mathrm{I}_{8} \mathrm{e}$ ${ }^{5} \mathrm{~F}_{5} \rightarrow{ }^{5} \mathrm{I}_{8}$. Este resultado sugere que dependendo da região de interesse pode-se escolher uma concentração de íons $\mathrm{Ho}^{3+}$ que atenda a requisitos pré-estabelecidos para determinadas aplicações.

\section{CONCLUSÃO}

Pós de tungstato de bário puro e dopado com hólmio $\left(\mathrm{Ba}_{1-\mathrm{x}} \mathrm{Ho}_{2 \times / 3} \mathrm{WO}_{4}, \mathrm{x}=0,0,01\right.$ e 0,02$)$ foram obtidos pelo método de coprecipitação à temperatura ambiente e caracterizados por difração de raios X, espectroscopia Raman, espectroscopia FT-IR, absorção na região do UV/Vis, microscopia eletrônica de varredura e medidas de fotoluminescência. Os padrões de difração de raios X, dados do refinamento de Rietveld e os espectros Raman indicaram que estes materiais apresentam estrutura tetragonal do tipo scheelita, 
com grupo espacial I41/a, de acordo com o arquivo JCPDS 43-0646, sem a presença de fases deletérias, mesmo após a incorporação de íons $\mathrm{Ho}^{3+}$ à estrutura. Houve diminuição significativa das intensidades dos picos de difração com a inserção dos íons dopantes, sugerindo que houve redução da cristalinidade. Além disso, as variações das posições atômicas do oxigênio sugeriram que o processo de dopagem induz perturbações nas ligações $\mathrm{Ba}-\mathrm{O}, \mathrm{W}-\mathrm{O}$ e $\mathrm{Ho}-\mathrm{O}$, e em consequência, distorções dos clusters $\left[\mathrm{BaO}_{8}\right],\left[\mathrm{HoO}_{8}\right]$ e $\left[\mathrm{WO}_{4}\right]$. Os espectros Raman exibiram 10 modos que indicaram que os pós cerâmicos apresentaram ordenamento cristalino a curto alcance. $\mathrm{O}$ estudo das larguras à meia altura (FWHM) dos espectros Raman, entretanto, ratificou a hipótese de que as amostras sofreram redução da cristalinidade quando os íons dopantes foram adicionados. Foram verificados pequenos deslocamentos Raman nos espectros atribuídos aos defeitos introduzidos nas celas unitárias com a adição de íons $\mathrm{Ho}^{3+} \mathrm{e}$ inerentes ao próprio método de síntese. Dois modos foram identificados nos espectros de FT-IR correspondentes aos estiramentos assimétricos $(\rightarrow \mathrm{O} \rightarrow \mathrm{W} \rightarrow \mathrm{O})$. As imagens de microscopia eletrônica de varredura mostraram que a adição de $\mathrm{Ho}^{3+}$ na matriz de $\mathrm{BaWO}_{4}$ promoveu alterações na morfologia, diminuindo a cristalinidade e induzindo um aumento do tamanho médio dos grãos. Os grãos de $\mathrm{BaWO}_{4}$ apresentaram forma de octaedros facetados com distribuição granulométrica heterogênea. Com a inserção dos íons hólmio à matriz, foi observada a formação de grãos com morfologia ainda mais heterogênea e polidispersa. As análises dos espectros de absorção no UV-Vis indicaram que a substituição dos íons $\mathrm{Ba}^{2+}$ por íons $\mathrm{Ho}^{3+}$ promove uma redução significativa nos valores do gap óptico devido ao surgimento de níveis energéticos intermediários no interior do gap. Uma banda larga centrada em $475 \mathrm{~nm}$ foi identificada no espectro de emissão de $\mathrm{BaWO}_{4}$ atribuída às transições $p \rightarrow d$ $\left(\mathrm{O}^{2-} \rightarrow \mathrm{W}^{6+}\right)$. Com a incorporação dos íons $\mathrm{Ho}^{3+}$, houve redução dessa banda e aparecimento das transições $f-f$ como bandas estreitas características dos íons $\mathrm{Ho}^{3+}$. $\mathrm{O}$ aumento da concentração nominal de 1 a $2 \%$ de $\mathrm{Ho}^{3+}$ induziu pequenos deslocamentos da região de emissão nos espectros para maiores comprimentos de onda. Além disso, houve um aumento da intensidade luminescente de ${ }^{5} \mathrm{G}_{6} \rightarrow{ }^{5} \mathrm{I}_{8} \mathrm{e}^{5} \mathrm{~F}_{3} \rightarrow{ }^{5} \mathrm{I}_{8}$ (região do azul) e redução da intensidade luminescente nas regiões do verde e do vermelho correspondentes às transições ${ }^{5} \mathrm{~F}_{4} /{ }^{5} \mathrm{~S}_{2} \rightarrow{ }^{5} \mathrm{I}_{8}$ e ${ }^{5} \mathrm{~F}_{5} \rightarrow{ }^{5} \mathrm{I}_{8}$.

\section{REFERÊNCIAS}

[1] S. M. Pourmortazavi, M. Taghdiri, N. Samimi, M. Rahimi-Nasrabadi, Mater. Lett. 121 (2014) 5.

[2] Y. Shen, W. Li, T. Li, Mater. Lett. 65, 19-20 (2011) 2956. [3] A. Phuruangrat, T. Thongtem, S. Thongtem, J. Phys. Chem. Solids 70, 6 (2009) 955.

[4] N. V. Pillai, V. P. M. Pillai, R. Vinodkumar, I. Navas, V. Ganesan, P. Koshy, J. Alloy. Compnd 509, 6 (2011) 2745.

[5] Z. Song, J. Ma, H. Sun, Y. Sun, W. Wang, J. Fang, Z. Liu, C. Gao, J. Am. Ceram. Soc. 92, 10 (2009) 2447.

[6] Z. Song, J. Ma, X. Li, Y. Sun, J. Fang, Z. Liu, C. Gao, J.
Am. Ceram. Soc. 92, 6 (2009) 1354.

[7] P. R. Lucena, F. M. Pontes, C. D. Pinheiro, E. Longo, P. S. Pizani, S. Lázaro, A. G. Souza, I. M. G. Santos, Cerâmica 50, 314 (2004) 138.

[8] L. S. Cavalcante, F. M. C. Batista, M. A. P. Almeida, A. C. Rabelo, I. C. Nogueira, N. C. Batista, J. A. Varela, M. R. M. C. Santos, E. Longo, M. Siu Li, RSC Adv. 2 (2012) 6438.

[9] P. Goel, R. Mithal, S. L. Chaplot, J. Phys. - Conf. Ser. 377 (2012) 1.

[10] P. Goel, R. Mithal, S. L. Chaplot, AIP Conf. Proc. 1313, 328 (2010) 328.

[11] V. Panchal, N. Garg, A. K. Chauhan, Sangeeta, S. M. Sharma, Solid State Comm. 130, 203 (2004) 203.

[12] S. Vidya, S. Solomon, J. K. Thomas, Adv. Cond. Matter Phys. 2013 (2013) 1.

[13] X. Sun, X. Li, X. Sun, J. He, B. Wang, J. Mater. Sci Mater. Elect. 25, 4 (2014) 1647.

[14] C. Cui, J. Bi, D. Gao, K. Zhao, J. Alloy.Compnd. 462, 1-2 (2008) 16.

[15] M. Tyagi, S. G. Singh, A. K. Chauhan, S. G. Gadkari, Physica B, 40521 (2010) 4530.

[16] H. Wang, Y. Wang, J. Zhang, N. Gaponik, A. L. Rogach, Mater. Sci. Eng. B - Adv. 179 (2014) 48.

[17] C. Wang, X. Zhang, Q. Wang, Z. Cong, Z. Liu, W. Wei, W. Wang, Z. Wu, Y. Zhang, L. Li, X. Chen, P. Li, H. Zhang, S. Ding, Opt. Express 21, 22 (2013) 26014.

[18] P. Afanasiev, Mater. Lett. 61, 23-24 (2007) 4622.

[19] Z. Luo, H. Li, J. Xia, W. Zhu, J. Guo, B. Zhang, Mater. Lett. 61, 8-9 (2007) 1845.

[20] A. I. Vodchits, V. A. Orlovich, P. A. Apanasevich, T. T. Basiev, P. G. Zverev, Opt. Mater. 29, 12 (2007) 1616.

[21] K. Ambast, A. K. Kunti, S. Som, S. K. Sharma, Appl. Opt. 52, 35 (2013) 8424.

[22] L. S. Cavalcante, J. C. Sczancoski, J. W. M. Espinosa, J. A. Varela, P. S. Pizani, E. Longo, J. Alloy. Compnd. 474, 1-2 (2009) 195.

[23] A. L. Al-Hajji, M. A. Hasan, M. I. Zaki, J. Therm. Anal. Calorim. 100, 1 (2010) 43.

[24] L. S. Cavalcante, J. C. Sczancoski, L. F. Lima, J. W. M. Espinosa, P. S. Pizani, J. A. Varela, E. Longo, Cryst. Growth Des. 9, 2 (2009) 1002.

[25] X. Gao, L. Lei, L. Kang, Y. Wang, Y. Lian, K. Jiang, J. Alloy. Compnd 585 (2014) 703.

[26] S. Park, S. Cho, J. Alloy. Compnd 584 (2014) 524.

[27] G. R. Dillip, K. Mallikarjuna, S. J. Dhoble, B. D. P. Raju, J. Phys. Chem. Solids 75, 1 (2014) 8.

[28] N. C. George, K. A. Denault, R. Seshadri, Annu. Rev. Mater. Res. 43 (2013) 481.

[29] M. C. Pujol, J. J. Carvajal, X. Mateos, R. Solé, J. Massons, M. Aguiló, F. J. Díaz, J. Lumin. 138 (2013) 77.

[30] P. Fabeni, A. Krasnikov, T. Kärner, V. V. Laguta, M. Nikl, G. P. Pazzi, S. Zazubovich, J. Lumin. 136 (2013) 42.

[31] G. Li, L. Li, M. Li, W. Bao, Y. Song, S. Gan, H. Zou, X. Xu, J. Alloy. Compnd. 550 (2013) 1.

[32] B. S. Barros, A. C. Lima, Z. R. Silva, D. M. A. Melo, S. C. Alves Jr., J. Phys. Chem. Solids 73, 5 (2012) 635. 
[33] E. C. Barros Filho, Diss. Mestrado, Prog. Pós-Grad. Tecnol. Nuclear - Materiais, IPEN-USP, SP (2012).

[34] T. A. Wollin, J. D. Denstedt, J. Clin. Laser Med. Surg. 16, 1 (1998) 13.

[35] H. M. Rietveld, J. Appl. Crystallogr. 2 (1969) 65.

[36] A. C. Larson, R. B. von Dreele, "General Structure Analysis System (GSAS)", Los Alamos National Laboratory Report LAUR (2004) 86.

[37] B. H. Toby, J. Appl. Crystallogr. 34 (2001) 210.

[38] H. M. Rietveld, Acta Crystallogr. 22 (1967) 151.

[39] T. F. Oliveira, Tese Dr., Prog. Pós-Grad. Eng. Prod., PUC, RJ (2005).

[40] W. C. Leite, Diss. Mestrado, Programa de PósGraduação em Ciências, UEPG, PR (2012).

[41] R. Sailer, G. McCarthy, North Dakota State University, Fargo, North Dakota, USA., ICDD Grant-in-Aid (1992).

[42] E. G. Vieira, P. A. A. Sousa, J. M. E. Matos, M. R. M. C. Santos, Cerâmica 59, 351 (2013) 417.

[43] N. S. Gonçalves, J. A. Carvalho, Z. M. Lima, J. M. Sasaki, Mater. Lett. 72 (2012) 36.

[44] V. D. Mote, Y. Purushotham, B. N. Dole, J. Theor. Appl. Phys. 6 (2012) 1.
[45] L. G. Pereira, L. E. B. Soledade, J. M. Ferreira, S. J. G. Lima, V. J. Fernandes Jr., A. S. Araújo, C. A. Paskocimas, E. Longo, M. R. C. Santos, A. G. Souza, I. M. G. Santos, J. Alloy. Compnd. 459, 1-2 (2008) 377.

[46] P. F. S. Pereira, A. P. Moura, I. C. Nogueira, M. V. S. Lima, E. Longo, P. C. Sousa F., O. A. Serra, E. J. Nassar, I. L. V. Rosa, J. Alloy. Compnd. 526 (2012) 11.

[47] B. Schrader, "General survey of vibrational spectroscopy", VCH Publishers Inc., New York, EUA (1995) p. 7

[48] D. L. Wood, J. Tauc, Phys Rev. B 5, 8 (1972) 3144.

[49] C. J. Jones, A química dos elementos dos blocos d e f, Ed. Bookman, Porto Alegre, RS (2002) p. 152.

[50] E. W. Barrera, M. C. Pujol, J. J. Carvajal, J. Mateos, R. Solé, J. Massons, A. Speghini, M. Bettinelli, C. Cascales, M. Aguiló, F. Diaz, Phys. Chem. Chem. Phys. 16, 4 (2014) 1679 .

[51] D. Thangaraju, A. Durairajan, S. Moorthy Babu, Y. Hayakawa, J. Alloy. Compnd. 509, 41 (2011) 9890.

[52] D. Haiyan, L. Yujing, X. Zhiguo, S. Jiayue, J. Rare Earths 28, 5 (2010) 697.

(Rec. 30/03/2015, Ac. 04/04/2015) 